\title{
PELATIHAN APLIKASI ASESMEN ANAK BERKEBUTUHAN KHUSUS DI SEKOLAH LUAR BIASA DAN INKLUSI KABUPATEN BANJAR
}

\author{
Fathul Hafidh $^{1}$, Mirza Yogy Kurniawan ${ }^{2}$, Mirnawati ${ }^{3}$ \\ ${ }^{1,2}$ Universitas Islam Kalimantan Muhammad Arsyad Al-Banjari, \\ Jalan Adhyaksa No.2 Kayu Tangi Banjarmasin, \\ ${ }^{3}$ Universitas Lambung Mangkurat, Jalan Brigjen. H. Hasan Basri, Banjarmasin \\ ${ }^{1}$ e-mail: hafidh@uniska-bjm.ac.id
}

\begin{abstract}
Abstrak
Anak berkebutuhan khusus (ABK) diistilahkan kepada anak yang memiliki kelainan/penyimpangan dalam hal fisik, mental maupun karakteristik anak pada umumnya. Pada kabupaten Banjar yaitu SDLBN Sungai Paring dan SDN Keraton 2 memberikan fasilitas pada pendidikan dasar bagi ABK terdapat Sekolah Dasar Luar Biasa, dan Sekolah Dasar Inklusi (Pendidikan dasar seperti biasa, akan tetapi juga menerima siswa ABK). Setiap Awal tahun ajaran dan akhir semester, diadakan asesmen kepada anak untuk mengetahui perkembangan tumbuh ABK. Kegiatan asesmen selama ini dilakukan oleh Guru Pendamping Khusus (GPK) dengan keterbatasan personil, media pembantu, keterbatasan waktu dan juga keterbatasan pengetahuan penunjang untuk proses asesmen. Pelaksanaan kegiatan terdiri dari 3 kegiatan utama yaitu pengembangan aplikasi APBAKUS ( Aplikasi Asesmen Anak Berkebutuhan Khusus), pelatihan di tempat mitra mengenai penggunaan aplikasi pada kedua mitra dan workshop dengan tema mengenal anak berkebutuhan khusus, pelaksanaan asesmen dan pelatihan penggunaan APBAKUS. Dengan adanya kegiatan ini GPK dapat dengan mudah melakukan asesmen terhadap ABK, mendapatkan kesimpulan asesmen yang telah dilakukan terhadap ABK, memudahkan pencarian data dan mendapatkan informasi dari asesmen agar pendidikan yang diberikan kepada ABK dapat dimaksimalkan.
\end{abstract}

Kata Kunci: Anak Berkebutuhan Khurus, Apbakus, Asesmen, Pendidikan Luar Biasa

\begin{abstract}
Children with special needs (ABK) are termed children who have abnormalities / deviations in physical, mental and characteristic of children in general. In Banjar district, namely Sungai Paring SDLBN and Keraton 2 SDN to provide facilities for basic education for ABK there are Extraordinary Primary Schools, and Inclusive Primary Schools (Basic education as usual, but also accept ABK students). Every Beginning of the school year and the end of the semester, assessment is held to the child to find out the development of ABK growth. Assessment activities have been carried out by Special Assistance Teachers (GPK) with limited personnel, supporting media, limited time and also limited supporting knowledge for the assessment process. The implementation of the activities consisted of 3 main activities, namely the development of the APBAKUS application (Application for Assessment of Children with Special Needs), training at partners' places on the use of applications for both partners and workshops with the theme of recognizing children with special needs, the implementation of assessment and training on the use of APBAKUS. With this activity, GPK can easily assess ABK, get conclusions of assessments made with $A B K$, facilitate data search and obtain information from assessments so that education provided to $A B K$ can be maximized.
\end{abstract}

Keywords: Children with Special Needs, Apbakus, Assessment, Special Education 


\section{PENDAHULUAN}

Anak berkebutuhan khusus (ABK) diistilahkan kepada anak yang memiliki kelainan/penyimpangan dalam hal fisik, mental maupun karakteristik anak pada umumnya (Abdullah, 2013). Penyelenggaraan pendidikan inklusif baik dari segi kondisi siswa, kualifikasi guru, sarana dan prasarana penunjang, dukungan orang tua maupun dukungan pemerintah pusat dan daerah belum semuanya sesuai dengan pedoman penyelenggaraan (Praptiningrum, 2010). Pendidikan pada ABK diharapkan mampu menjadikan ABK mandiri, tidak tergantung dengan orang lain dan mungkin dapat mengembangkan bakat lain yang menjadikan ABK memiliki kemampuan untuk dikembangkan dan ditunjukkan sebagai pribadi yang berkembang (Awwad, 2015).

Daerah Kabupaten Banjar untuk memfasilitasi pendidikan dasar bagi ABK terdapat Sekolah Dasar Luar Biasa, dan Sekolah Dasar Inklusi (Pendidikan dasar seperti biasa, akan tetapi juga menerima siswa ABK). Setiap Awal tahun ajaran dan akhir semester, diadakan asesmen kepada anak untuk mengetahui perkembangan tumbuh ABK. Kegiatan asesmen selama ini dilakukan oleh Guru Pendamping Khusus (GPK) dengan keterbatasan personil, media pembantu, keterbatasan waktu dan juga keterbatasan pengetahuan penunjang untuk proses asesmen. Keberhasilan implementasi kebijakan pengelolaan asesmen dilakukan dengan membagi pihak yang berperan dalam mengelola pendidikan, mengembangkan kerangka kerja berdasar kebijakan pusat dan mengaloksikan sumber daya dengan memperbantukan GPK (Yuliawan, 2017).

Menurut GPK yang berada pada sekolah inklusi, proses asesmen memiliki banyak kendala, terutama jumlah guru GPK yang merupakan lulusan pendidikan luar biasa hanya sekitar 30\%, sisanya 70\% adalah guru GPK alumni Pendidikan Guru Sekolah Dasar. Kemudian proses analisis asesmen sendiri masih menggunakan kertas dalam pencatatan, sehingga ketika ingin mengulang asesmen harus membongkar penyimpanan kertas dokumen dan juga sering terjadi kehilangan data asesmen anak karena terselip di dokumen lain. Dari hasil prates didapatkan pelaksanaan asesmen pada kedua mitra yaitu pada SD Keraton 4 Martapura (mitra a) 50\%, sedangkan pada mitra SDLBN 2 Sungai Paring (mitra 
b) $54.5 \%$ menyatakan waktu yang dibutuhkan dalam melaksanakan asesmen ABK selama 1 bulan. Sedangkan untuk analasis hasil asesmen, mitra a 75\% dan mitra b 64.6\% menyatakan memerlukan waktu 1 bulan.

Tabel 1. Hasil Kuisoner Prates

\begin{tabular}{lccc}
\hline \multicolumn{1}{c}{ Jenis Komponen } & Jawaban & mitra a & mitra b \\
\hline Berapa lama waktu yang & 1 bulan & 6 & 6 \\
dibutuhkan dalam & 2 minggu & 4 & 3 \\
melaksanakan asesmen ABK? & 1 Minggu & 2 & 2 \\
\hline Berapa lama waktu yang & 1 bulan & 9 & 7 \\
dibutuhkan dalam & 2 minggu & 3 & 3 \\
menganalisis hasil asesmen? & 1 Minggu & 0 & 1 \\
\hline Bagaimana proses pencarian & tidak terkoordinir & 7 & 9 \\
dan pengelolaan data hasil & terkoordinir \& lama & 5 & 2 \\
asessmen selama ini & cepat dan terkoordinir & 0 & 0 \\
\hline Apakah anda menemui & Sering & 8 & 4 \\
kendala/ hambatan dalam & Kadang-kadang & 4 & 7 \\
melaksanakan asesmen ABK? & & & 11 \\
\hline Jumlah Peserta & & 12 & 11 \\
\hline
\end{tabular}

Target yang ingin dicapai yakni memudahkan proses asesmen anak, meningkatkan pengetahuan GPK dalam kegiatan asesmen ABK, meningkatkan kemampuan mitra dalam menerapkan teknologi informasi, dengan adanya program ini juga diharapkan dapat meningkatkan kemampuan ABK dikarenakan proses asesmen yang lebih efektif dan efisien.

Untuk memudahkan proses asesmen dengan menggunakan aplikasi yang telah ada dan mengembangkan aplikasi tersebut, sehingga keberlangsungan dari aplikasi tetap berlanjut (Ihantola, 2010). Aplikasi yang akan digunakan dan dikembangkan pada kegiatan PKM ini yaitu Aplikasi Asesmen Anak Berkebutuhan Khusus (APBAKUS) yang telah dibuat pada tahun 2018 (Kurniawan, 2018). 


\section{METODE}

Pelaksanaan kegiatan PKM terdiri dari 3 kegiatan utama yaitu pengembangan aplikasi APBAKUS, training pada kedua mitra dan workshop mengenai anak berkebutuhan khusus, asesmen dan pelatihan penggunaan Aplikasi Anak Berkebutuhan Khusus (APBAKUS).

\section{Penyempurnaan Aplikasi Anak Berkebutuhan Khusus (APBAKUS)}

Aplikasi APBAKUS telah dikembangkan pada 2018 dengan kegiatan ini dilakukan penyempurnaan agar implementasi dapat berjalan dengan baik, penyempurnaan dilakukan hingga kegiatan selesai. Adapun fitur yang ditambahkan pada APBAKUS yaitu: (1) Kategorisasi butir instrumen; (2) Penambahan data instrumen; (3) Rekapitulasi hasil asesmen sebagai bahan analisis GPK.

\section{Pelatihan Pada Lokasi Mitra}

Pelatihan dilakukan pada kedua mitra yaitu SDLBN Sungai Paring (mitra a) dan SDN Keraton 2 (mitra b) dengan tujuan memperkenalkan aplikasi sekaligus uji aplikasi daring dengan pengimplementasian langsung. Uji coba dilakukan terlebih untuk mengetahui kelancaran dalam proses registrasi, pengiriman email verifikasi pendaftaran dan uji coba proses asesmen oleh GPK. Proses pelatihan ini juga bersifat perkenalan kepada GPK sehingga mengenal APBAKUS terlebih dahulu sebelum dilaksanakannya workshop, bagi tim pelaksanaan kegiatan mendapatkan umpan balik berupa masukan ataupun saran terkait aplikasi itu sendiri.

\section{Workshop}

Workshop merupakan kegiatan utama dari rangkaian Pelatihan Aplikasi Asesmen Anak Berkebutuhan Khusus di SD LB dan Inklusi Kab. Banjar. Kegiatan dibuka oleh Kepala Pusat Pengabdian LP2M UNISKA Ibu Dr. Nurul Listiyani, SH., MH. Serah terima hibah pengabdian berupa komputer tablet serta manual APBAKUS. Kemudian dilanjutkan materi Pengenalan dan Pedoman Pendidikan Anak Berkebutuhan Khusus, Kedudukan Asesmen dalam Pendidikan Anak Berkebutuhan Khusus. Pada Workshop ini juga dilaksanakan Launching 
dan pengenalan APBAKUS serta pelatihan penggunaan APBAKUS dalam asesmen ABK.

\section{Monitoring Implementasi APBAKUS}

Proses pendampingan dan peninjauan pengimplementasian APBAKUS pada mitra a dan mitra b. Proses ini dilakukan untuk melihat dampak pemanfaatan dari sisi aplikasi.

\section{Posttest dan Evaluasi Hasil}

Setelah implementasi berjalan dan penerapan berlangsung dengan baik, selanjutnya dilakukan postes untuk mengukur dan membandingkan sebelum dilaksanakan kegiatan pengabdian dengan setelah dilaksanakannya serangkaian kegiatan pengabdian.

\section{HASIL DAN PEMBAHASAN}

\section{Penyempurnaan Aplikasi Anak Berkebutuhan Khusus (APBAKUS)}

Adapun penambahan fitur yang telah ditambahkan berdasarkan hasil dari uji coba pada mitra dan proses training mitra serta workshop didapatkan: Kategorisasi butir instrumen, fitur ini ditambahkan untuk memudahkan pemasukan butir-butir instrumen saat proses asesmen dilakukan. Dengan adanya fitur ini dapat memudahkan pemilihan instrumen yang diberikan kepada ABK.

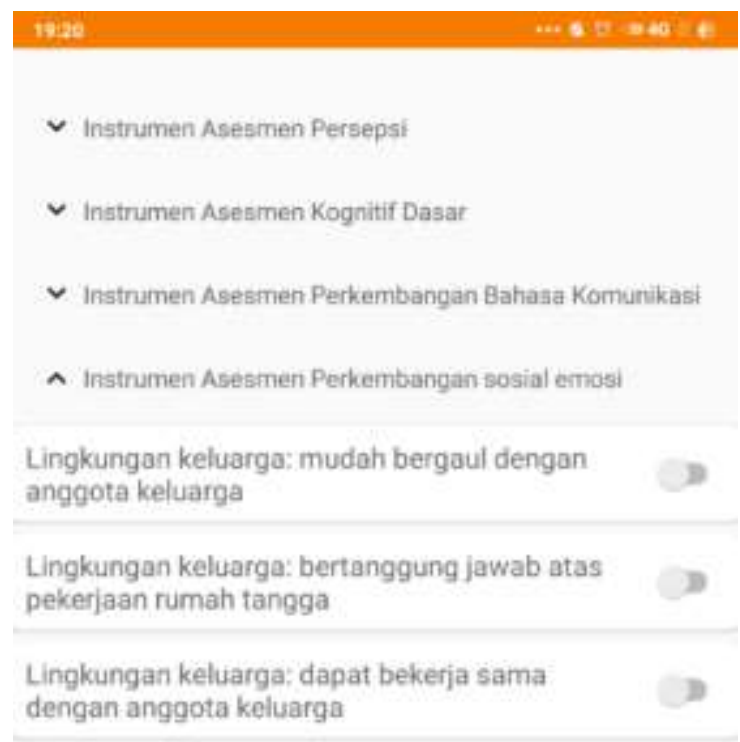

Gambar 1. Kategorisasi Butir Instrumen 
Penambahan data instrumen, Fitur ini menambahkan data instrumen yang telah dikonsultasikan dan disesuaikan dengan penggunaan asesmen pada tempat mitra, instrumen yang disetujui merupakan instrumen yang telah dikembangkan oleh Pendidikan Luar Biasa Universitas Lambung Mangkurat. Adapun fitur instrumen yang ditambahkan adalah (1) Instrumen Asesmen Persepsi, (2) Instrumen Asesmen Kognitif dasar, (3) Instrumen Asesmen Perkembangan sosial emosi, (4) Instrumen Asesmen Perkembangan Motorik.

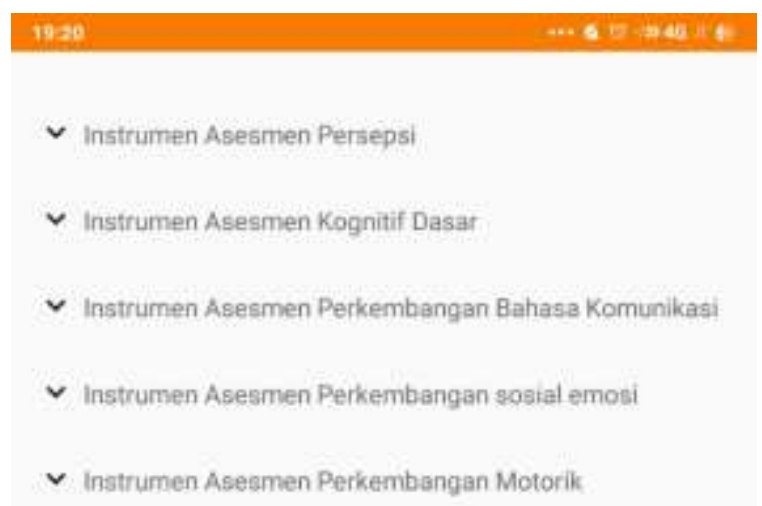

\section{Gambar 2. Penambahan Instrumen Asesmen}

Rekapitulasi Hasil Asesmen Sebagai Bahan Analisis GPK, fitur rekapitulasi merupakan fitur yang memudahkan analisis pada asesmen yang telah dilaksanakan, rekapitulasi mempresentasikan butir-butir pada tiap kategori instrumen sehingga memudahkan GPK dalam memberikan penilaian, ataupun mengetahui peningkatan hasil asesmen pada asesmen berikutnya (Triyanto, 2008).

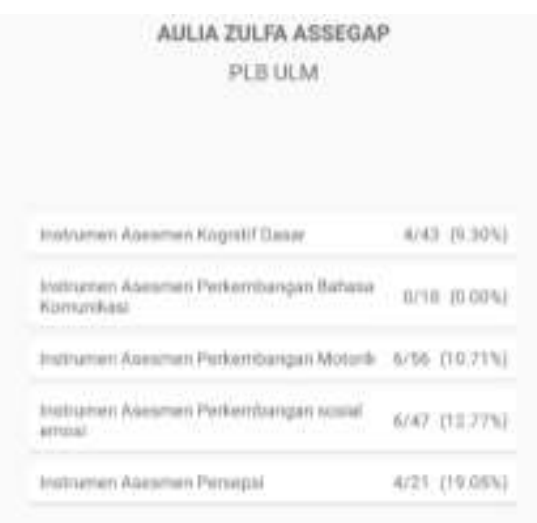

Gambar 3. Rekapitulasi Hasil Asesmen 


\section{Pelatihan Pada Lokasi Mitra}

Training dilakukan pada kedua mitra dengan tujuan memperkenalkan aplikasi sekaligus uji aplikasi daring dengan pengimplementasian langsung. Uji coba dilakukan untuk mengetahui kelancaran dalam proses registrasi, pengiriman email verifikasi pendaftaran dan uji coba proses asesmen oleh GPK. Proses pelatihan ini juga bersifat perkenalan kepada GPK sehingga mengenal APBAKUS terlebih dahulu sebelum dilaksanakannya workshop, bagi tim kegiatan itu sendiri mendapatkan manfaat berupa masukan ataupun saran untuk aplikasi yang di buat agar memaksimalkan manfaat dari aplikasi. Dokumentasi video kegiatan awal hingga training telah didokumentasikan dan bisa diakses pada pranala https://www.youtube.com/watch?v=eC14LqzSIT0.

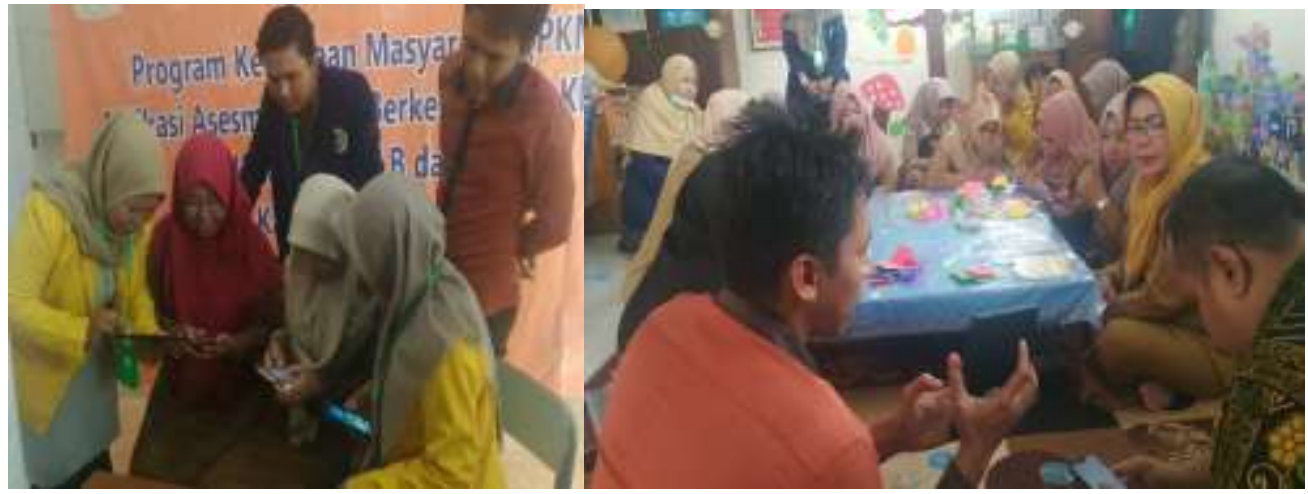

\section{Gambar 4. Pelaksanaan Training Pada Mitra A Dan Mitra B}

\section{Workshop}

Workshop merupakan kegiatan utama dari rangkaian pengabdian Aplikasi Asesmen Anak Berkebutuhan Khusus di SD LB dan Inklusi Kab. Banjar. Kegiatan dibuka oleh Kepala Pusat Pengabdian LP2M UNISKA Ibu Dr. Nurul Listiyani, SH., MH. Serah terima hibah PKM berupa Komputer tablet serta manual APBAKUS. Kemudian dilanjutkan materi Pengenalan dan Pedoman Pendidikan Anak Berkebutuhan Khusus (Zaitun, 2018), Kedudukan Asesmen dalam Pendidikan Anak Berkebutuhan Khusus (Tyas Leylasari, 2015). Launching dan pengenalan APBAKUS, pelatihan penggunaan APBAKUS dalam asesmen ABK. Dokumentasi video dari kegiatan workshop yang telah dilaksanakan, telah diunggah dan dapat diakses pada pranala https://www.youtube.com/watch?v=FWzuQDIEWbY. 


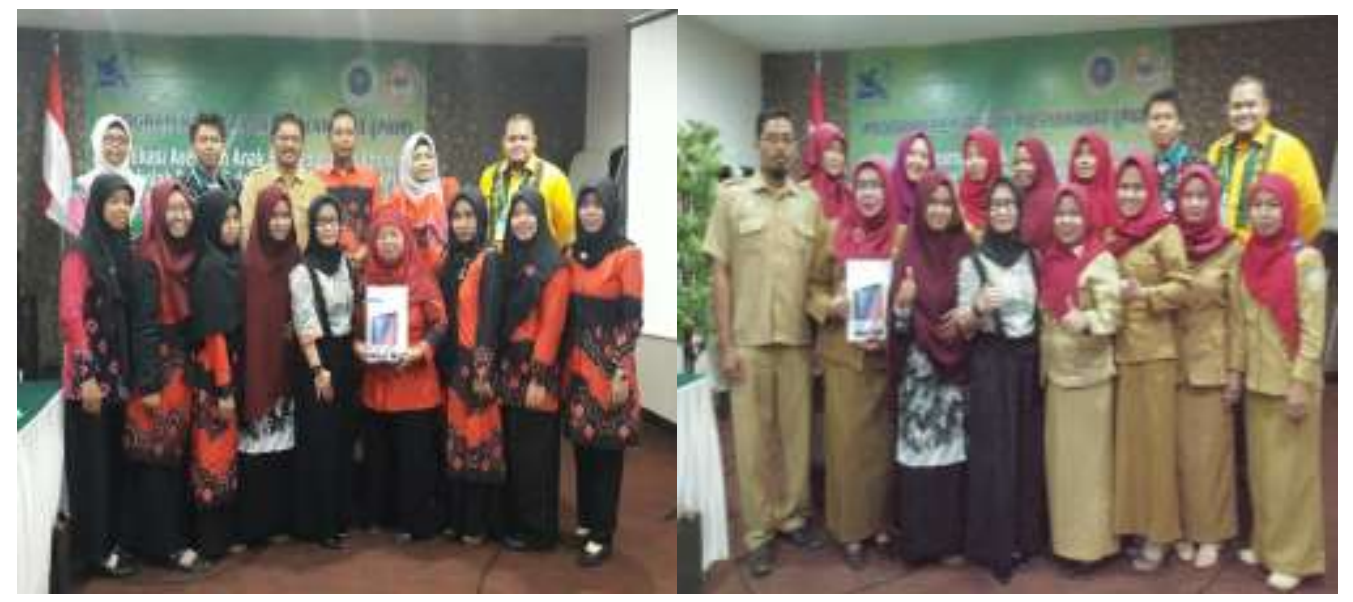

Gambar 5. Foto Bersama Kegiatan Workshop Dengan Mitra A Dan Mitra B Monitoring Implementasi APBAKUS

Pendampingan dan peninjauan pengimplementasian APBAKUS pada mitra a dan mitra $b$ dilakukan untuk melihat seberapa besar pemanfaatan aplikasi oleh mitra. Pada Proses ini ditemukan pada mitra a, data siswa yang telah diinput sebanyak 72 siswa, sedangkan pada mitra b sebanyak 21 siswa.

\section{Posttest dan Evaluasi Hasil}

Hasil posttes menunjukkan peningkatan terutama pada kecepatan pelaksanaan asesmen, yang mana didapatkan 73,9\% GPK dari mitra a maupun mitra $b$ rata-rata waktu kurang dari 1 minggu. Kemudian untuk dapat menyelesaikan penyajian analisis asesmen, GPK mitra a dan mitra b sebanyak $65.2 \%$ memerlikan waktu kurang dari 1 minggu. Pencarian data asesmen yang sebelumnya tidak terkoordinir, setelah evaluasi didapatkan $78.8 \%$ menyatakan dengan adanya aplikasi APBAKUS menjadi cepat dan terkoordinir. Begitu pula dengan kendala pelaksanaan asesmen, setelah diberikan pelatihan dan juga pemberian materi tentang asesmen $82.6 \%$ GPK tidak lagi sering mengalami kendala. 
Tabel 2. Hasil Kuisoner Posttest

\begin{tabular}{lccc}
\hline \multicolumn{1}{c}{ Jenis Komponen } & Jawaban & mitra a & mitra b \\
\hline Berapa lama waktu yang & 1 bulan & 1 & 0 \\
dibutuhkan dalam & 2 minggu & 2 & 3 \\
melaksanakan asesmen ABK? & 1 Minggu & 9 & 8 \\
\hline Berapa lama waktu yang & 1 bulan & 1 & 1 \\
dibutuhkan dalam & 2 minggu & 2 & 4 \\
menganalisis hasil asesmen? & 1 Minggu & 9 & 6 \\
\hline Bagaimana proses pencarian & tidak terkoordinir & 0 & 0 \\
dan pengelolaan data hasil & terkoordinir \& lama & 3 & 2 \\
asessmen selama ini & cepat dan terkoordinir & 9 & 9 \\
\hline Apakah anda menemui & Sering & 3 & 0 \\
kendala/ hambatan dalam & Kadang-kadang & 8 & 11 \\
melaksanakan asesmen ABK? & & & \\
\hline Jumlah Peserta & & $\mathbf{1 2}$ & $\mathbf{1 1}$ \\
\hline
\end{tabular}

\section{SIMPULAN}

Kesimpulan yang didapatkan dari pelaksanaan PKM yang telah terlaksana ini adalah (1) Kegiatan pengabdian mampu meningkatkan kecepatan pelaksanaan asesmen terhadap siswa, dari ketika pretest baik mitra a maupun b mendapati ratarata waktu kurang dari dua minggu saat postes mitra a dan b 73,9\% menjawab kurang dari 1 minggu, (2) Penerapan aplikasi APBAKUS menarik minat GPK dan memudahkan GPK dalam proses pemberian instrumen, pelaksanaan asesmen analisis hasil asesmen dan informasi riwayat asesmen, (3) GPK pada mitra mendapatkan pengetahuan mengenai permasalahan dalam pendidikan $\mathrm{ABK}$ dan proses asesmen secara menyeluruh dalam kegiatan workshop.

\section{UCAPAN TERIMA KASIH}

Terima Kasih diucapkan atas dana hibah Program Kemitraan Masyarakat (PKM) tahun 2019 yang telah diberikan oleh Kementerian Riset Teknologi dan Pendidikan Perguruan Tinggi (Kemristekdikti), kepada Lembaga Penelitian dan dan Pengabdian Kepada Masyarakat (LPPM) Universitas Islam Kalimantan 
(UNISKA) Muhammad Arsyad Al Banjari Banjarmasin atas bimbingan dalam perencanaan hingga pelaksanaan kegiatan PKM dan SDLBN 2 Martapura juga SDN Keraton 4 Martapura telah berpartisipasi sebagai mitra.

\section{DAFTAR PUSTAKA}

Abdullah, N. (2013). Mengenal anak berkebutuhan khusus. Magistra, 1, 1-10.

Awwad, M. (2015). Urgensi layanan bimbingan dan konseling bagi anak berkebutuhan khusus. Al-Tazkiah: Jurnal Bimbingan dan Konseling Islam, 46-64.

Ihantola, P. A. (2010). Review of recent systems for automatic assessment of programming assignments. In Proceedings of the 10th Koli calling international conference on computing education research, 86-93.

Kurniawan, M. Y. (2018). Rancang bangun aplikasi asesmen anak berkebutuhan khusus pada sekolah inklusif. Jurnal Teknologi Informasi Universitas Lambung Mangkurat (JTIULM), 77-82.

Praptiningrum, N. (2010). Fenomena penyelenggaraan pendidikan inklusif bagi anak berkebutuhan khusus. JPK (Jurnal Pendidikan Khusus), 7(2).

Tyas Leylasari, H. (2015). Pengembangan panduan identifikasi dan asesmen siswa berkebutuhan khusus di SDN inklusi X Surabaya. Widya Warta, 1-39.

Yuliawan, E. R. (2017). Implementasi kebijakan pengelolaan asesmen anak berkebutuhan khusus sekolah inklusi di dinas pendidikan pemuda dan olahraga provinsi DIY. Spektrum Analisis Kebijakan Pendidikan, 379-386.

Zaitun. Pendidikan anak berkebutuhan khusus, (Online), (http: osf.io/3v7yq/, diakses 3 April 2018). 